\title{
First report of Coniella hibisci causing leaf and stem canker in the Lao P.D.R.
}

\author{
Nicholas A. Pain ${ }^{1} \cdot$ Bevan S. Weir ${ }^{2} \cdot$ Lester W. Burgess $^{3} \cdot$ Sengphet Phanthavong $^{4} \cdot$ Virgilio Balmas $^{5}$. \\ Michael Schneider ${ }^{6}$
}

Received: 20 March 2019 / Accepted: 1 July 2019 / Published online: 8 July 2019

(C) Australasian Plant Pathology Society Inc. 2019

\begin{abstract}
Coniella hibisci is reported for the first time in Lao P.D.R. The pathogen was isolated from roselle (Hibiscus sabdariffa var. sabdariffa) stem and leaf samples from a farm in Thateng district, Sekong province, and deposited with the International Collection of Microorganisms from Plants (ICMP). The identification of the pathogen was based on morphological features and the results of sequencing the ITS, LSU, and tef1 genetic loci. Pathogenicity tests on four-week-old roselle plants reproduced field symptoms, satisfying Koch's postulates.
\end{abstract}

Keywords Laos $\cdot$ Coniella hibisci $\cdot$ Hibiscus sabdariffa $\cdot$ Roselle

The genus Coniella contains 30 accepted species and is a globally distributed plant pathogen with a wide host range, including Eucalyptus (Myrtaceae), Fragaria (Rosaceae), Hibiscus (Malvaceae), Terminalia (Combretaceae), and Vitis (Vitaceae) (Marin-Felix et al. 2017). Alvarez et al. (2016) recently revised the genus based on the phylogenetic and morphological analysis of 117 isolates of Coniella, Pilidiella and their teleomorphs in Schizoparme, concluding that all isolates clustered in a single clade are synonymous, and therefore should be referred to by their earliest name, Coniella. Species within this genus are known to cause leaf, stem, fruit and root infections as primary and opportunistic pathogens. Coniella hibisci (B. Sutton) Crous infects roselle (Hibiscus sabdariffa var. sabdariffa) leaves, stems and fruits and is an important disease in roselle crops grown in tropical regions of

Nicholas A. Pain

alhakawatie@gmail.com

Bevan S. Weir

WeirB@landcareresearch.co.nz

Lester W. Burgess

burgess.international@gmail.com

Sengphet Phanthavong

sengphetphanthavong@gmail.com

Virgilio Balmas

balmas@uniss.it

Michael Schneider

k.michael.schneider@gmail.com the world (Apeyuan et al. 2017; Persad and Fortune 1989). Roselle is an economically important crop in parts of Africa, Thailand and China, where it is grown for its medicinal and health benefits (Plotto 2004).

In November 2017 leaf spot, stem canker, and fruit rot were observed on the leaves, stems, and fruits of roselle plants at a farm (N: $15^{\circ} 27^{\prime} 29.772^{\prime \prime}$, E: $106^{\circ} 27^{\prime} 21.96$ ”) in Thateng district, Sekong province, Lao P.D.R. The roselle was being grown in sandy loamy silt soil with no irrigation. Pycnidia were observed on the brown necrotic areas of leaves, stems, and calyces (Fig. 1b). Infected leaves were blighted, became necrotic, and abscissed, leaving plants severely defoliated (Fig. 1a). Stem infections resulted in browning and narrowing of the stem, and some plant stems collapsed at the infection point, unable support the upper portion of the plant. Calyx

1 Agriculture section, Provincial Agriculture and Forestry Office,

Savannakhet, Savannakhet Province, Lao PDR

2 Landcare Research, Private Bag 92170, Auckland 1142, New Zealand

3 School of Biological Sciences, Faculty of Science, The University of Sydney, Sydney, NSW, Australia

4 Agriculture section, Provincial Agriculture and Forestry Office, Pakse, Champasak Province, Lao PDR

5 Dipartimento di Agraria, Università degli Studi di Sassari, Via E. De Nicola 9, 07100 Sassari, Italy

6 Mai Savanh Lao, Tateng, Sekong Province, Lao PDR 


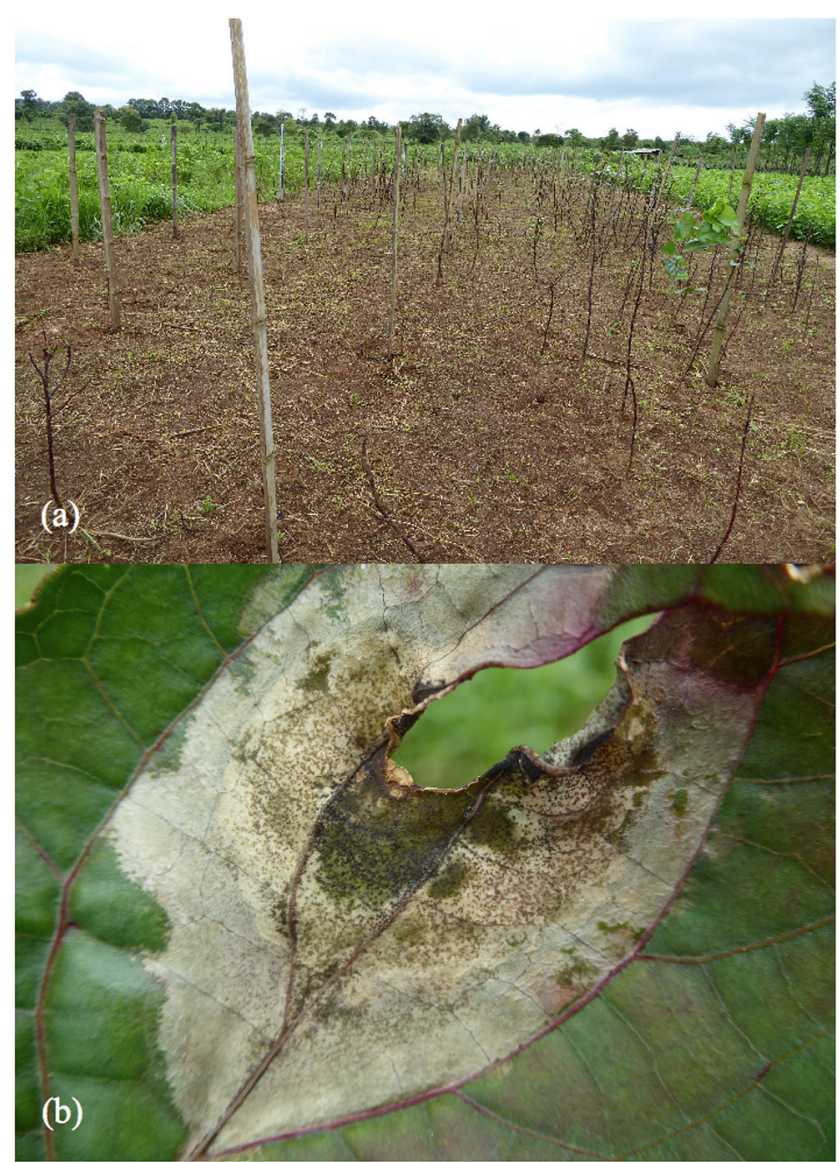

Fig. 1 Severe infection of roselle (Hibiscus sabdariffa) plants by Coniella hibisci at a farm in Thateng district, Sekong Province. a Coniella hibisci infection causing leaf abscission on roselle plants; b Pycnidia development on the necrotic tissue of a wounded and infected roselle leaf

infection caused premature desiccation and browning of the flowers. Approximately $80 \%$ of roselle plants on the farm were affected by these symptoms. Two weeks before these observations, the farm had been affected by a violent storm and strong winds. This event resulted in damage to leaves, stems, and flowers (calyces). Lesions were usually associated with damaged tissue.

Samples of symptomatic leaves and stems were collected and placed into individual plastic bags. The putative pathogen was isolated as follows. Tissue sections (approximately $3 \mathrm{~mm} \times 5 \mathrm{~mm}$ ) were cut from the margin of the necrotic lesions and washed in sterile water, immersed in $70 \%$ ethanol for $2 \mathrm{~s}$, immediately rinsed in sterile water, then dried on a clean paper towel. The sections were then placed on water agar (WA) plates amended with $500 \mathrm{mg} / \mathrm{L}$ of cephalexin and incubated at room temperature. After 3 days, colonies had developed from the tissue sections, and they were subcultured onto potato dextrose agar (PDA) plates amended with $500 \mathrm{mg} /$ L of cephalexin. Dark pycnidia formed readily on PDA after
3 days (Fig. 2a and b). Conidia were hyaline and ellipsoidal, black, and ranged in diameter from 100 to 400 um (Fig. 2c). This is consistent with the morphology of the epitype of C. hibisci described by Marin-Felix et al. (2017). Cultures were purified by hyphal tipping. Three purified cultures isolated from leaf and stem tissues were sent to the International Collection of Microorganisms from Plants (ICMP), Landcare Research, Auckland, New Zealand, for storage and identification by sequencing (https://www.landcareresearch.co.nz/ icmp).

DNA was extracted from mycelium using the Roche REDExtract-N-Amp Plant PCR Kit following the manufacturer's instructions. ITS and LSU loci were amplified using standard conditions (primers ITS1F / ITS4 and LR0R / LR5) (Johnston et al. 2017). The translation elongation factor 1alpha (tef1) was amplified with the EF1 and EF2 primers using the PCR conditions described in O'Donnell et al. (1998). Resulting PCR amplicons were sequenced using an ABI PRISM_3700DNA Analyser (Applied Biosystems Inc. Foster City, California, USA). Sequences deposited in GenBank as LSU (MK587719-MK587722), ITS (MK587740-MK587743), and tef1 (MK598700MK598703). LSU sequences confirmed the generic classification as Coniella. ITS sequences matched $C$. hibisci but were also very similar to $C$. fusiformis, thus sequences of the more variable protein coding gene tefl were used to construct a phylogenetic tree using MrBayes for 5 million generations with a $10 \%$ burning (Fig. 3) (Ronquist et al. 2012). The Lao P.D.R isolates grouped with the epitype culture of $C$. hibisci CBS 109757, and were distinct from all other species, including C. javanica, a pathogen of Hibiscus sabdariffai in Indonesia.

A pathogenicity test was undertaken on four-week old roselle plants grown in $10 \mathrm{~cm}$ potting bags with $50 \%$ potting mix and 50\% sand in a greenhouse, which were hand watered daily. A sterilised roselle leaf, and a PDA plug of C. hibisci were placed on a PDA plate, and incubated under fluorescent light at room temperature for one week, or until pycnidia could be seen on the leaf surface. Approximately $3 \mathrm{~cm}^{2}$ of this colonised leaf was then used as inoculum to infect six wounded and six non-wounded roselle plant leaves. One leaf per plant was inoculated in this way. Wounds were made by gently scraping a $2 \mathrm{~cm}^{2}$ area in the middle of the leaf surface $6-8$ times with a scalpel without puncturing the leaf. The inoculum was placed directly on the wounded area of the leaf (Fig. 4a). Six wounded and six non-wounded control leaves received an approximately $3 \mathrm{~cm}^{2}$ section of sterilised roselle leaf that had not been colonised by $C$. hibisci. All of the wounded infected leaves developed large brown lesions 4-6 days post inoculation (Fig. 4b), and pycnidia were observed on the necrotic leaf and stem tissue 7-14 days post inoculation. In one instance, 
Fig. 2 Morphological

characteristics of Coniella hibisci isolated from roselle. a Colony with abundant small black pycnidia on potato dextrose agar; $\mathbf{b}$ Globose black pycnidium releasing conidia from circular ostiole; c Hyaline, ellipsoid, inequilateral conidia
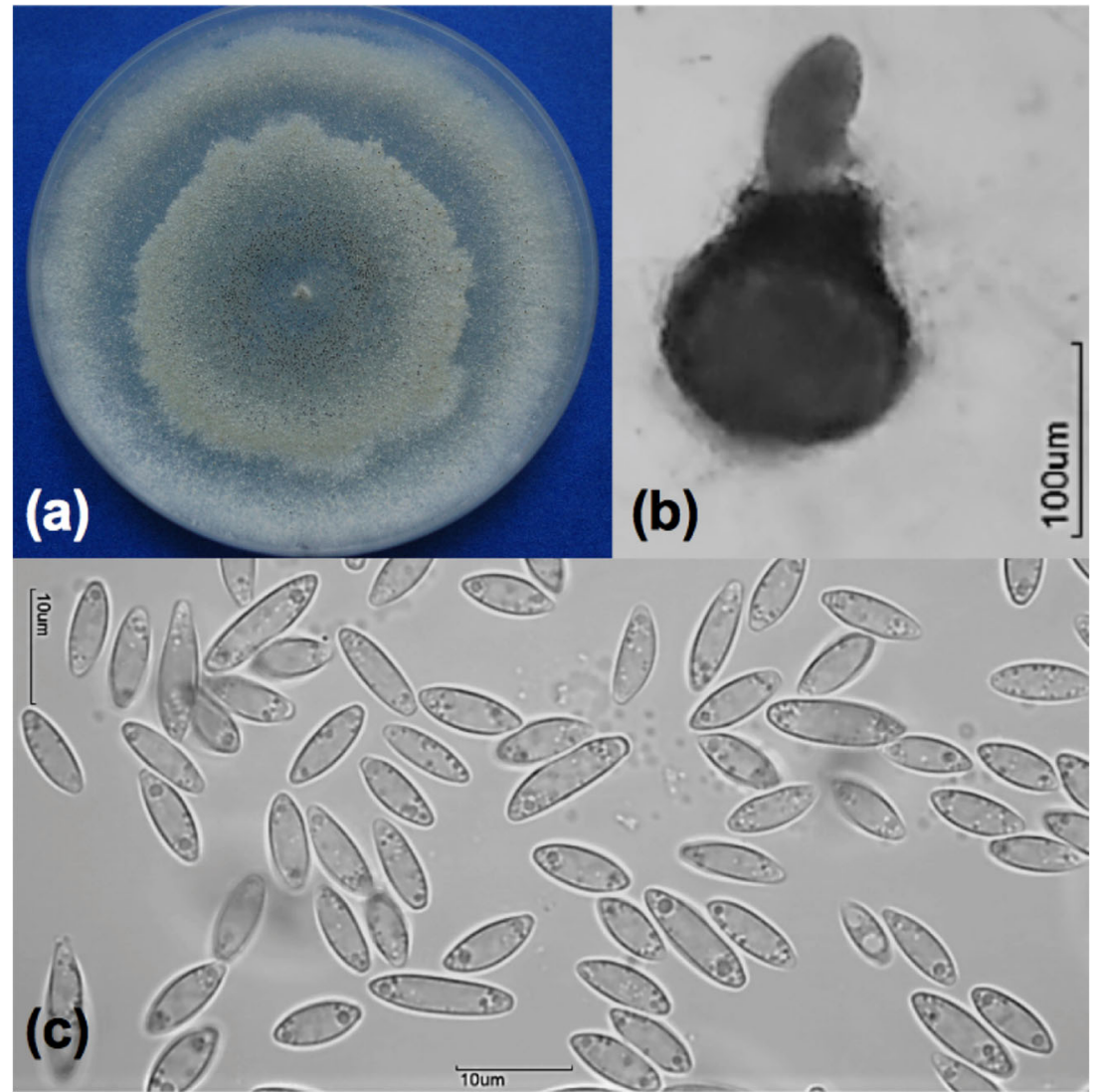

the infection spread down the petiole to the stem, where stem browning occurred and after three weeks the stem collapsed (Fig. 4c). Leaves from the non-wounded control, non- wounded infected, and wounded control treatments did not develop lesions and no pycnidia were observed. A second pathogenicity test was undertaken using sterilised water with

Fig. 3 Phylogenetic tree of $t e f 1$ gene sequences analysed with Bayesian inference. Numbers at nodes indicate posterior probabilities. Type or ex-type cultures indicated with "T"

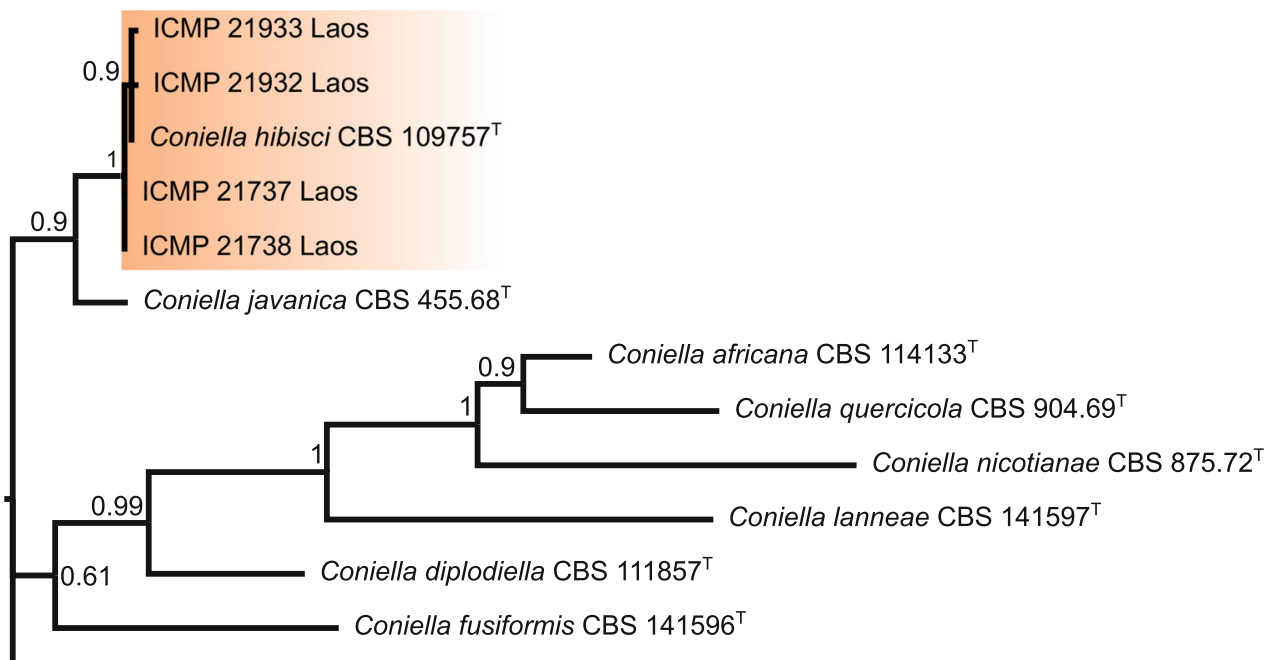

Tubakia paradryinoides MUCC $2294^{\top}$ 
Fig. 4 Pathogenicity testing. a Inoculation with sterilised roselle (Hibiscus sabdariffa) leaf tissue colonised by Coniella hibisci placed on a wound site on a roselle leaf; b Wounded and infected leaf four days post inoculation. The necrotic lesion has spread beyond the initial wound site and the leaf has abscissed; c Wounded and infected leaf 24 days post inoculation. The necrotic lesion has spread down the petiole to the stem, causing stem collapse, and pycnidial development on the necrotic leaf and stem tissue

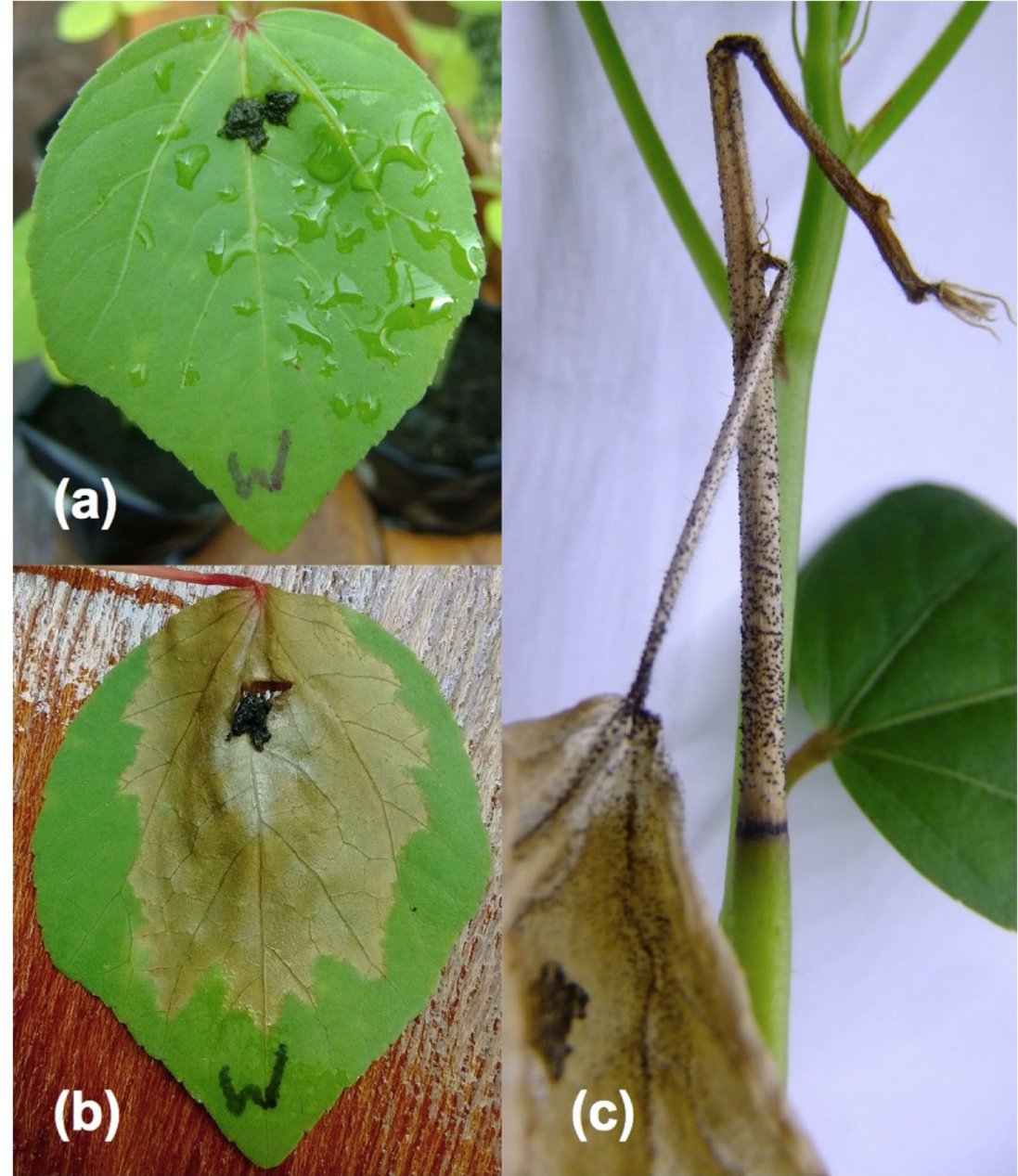

approximately $10^{6}$ conidia/mL as inoculum in place of colonised roselle leaves, and similar results were obtained. C. hibisci was reisolated from the wounded infected leaves in both pathogenicity tests using the isolation method described earlier, fulfilling Koch's postulates.

Okra (Abelmoschus esculentus) plants were also inoculated using the method described above for the first pathogenicity test but using colonised okra leaves as inoculum to determine if this common vegetable grown in the region, also in the Malvaceae family, was also susceptible to this isolate. Neither wounded nor non-wounded okra leaves developed lesions or pycnidia, and the experiment was repeated with colonised roselle leaves as inoculum, producing the same result.

This study is consistent with a previous report of $C$. hibisci in Trinidad and Tobago by Persad and Fortune (1989), which found that wounding is required for infection and symptom development, indicating that $C$. hibisci is an opportunistic pathogen on roselle. This finding corresponds with the observation that the severe outbreak of the disease followed a storm that caused wounding to the leaves and stems. Presumably the storm also dispersed conidia of $C$. hibisci and infected roselle debris widely, creating ideal infection conditions.

There is a growing global market for roselle and it is an economically important crop in neighbouring Thailand where high quality roselle is grown for export (Plotto 2004). To the authors knowledge no studies have been undertaken on the effect of $C$. hibisci on crop yield. Given the findings of this study, and earlier studies in Africa, further research into the impact of this disease in the region would be valuable. Furthermore, studies on the host range of this pathogen would be beneficial to developing disease management techniques.

Acknowledgments Financial support from The Crawford Fund of Australia is gratefully acknowledged. The authors also acknowledge the support provided by the Provincial Agriculture and Forestry Offices in Savannakhet and Champasak provinces. The first author is a volunteer with Australian Volunteers International (AVI), an Australian government program. BS Weir was supported through the Manaaki Whenua Landcare Research Characterising Land Biota Portfolio with funding from the Science and Innovation Group of the New Zealand Ministry of Business, Innovation and Employment. 


\section{References}

Alvarez L, Groenewald M, Crous PW (2016) Revising the Schizoparmaceae: Coniella and its synonyms Pilidiella and Schizoparme. Stud Mycol 85:1-34. https://doi.org/10.1016/j. simyco.2016.09.001

Apeyuan KD, Nwankiti AO, Oluma OAH, Ekefan EJ (2017) Effect of different sowing dates on disease initiation and development of Roselle (Hibiscus sabdariffa L.) leaf spot disease caused by Coniella musaiensis Var. hibisci in Makurdi, Central Nigeria. J Geosci Environ Prot 5:94-101. https://doi.org/10.4236/gep.2017. 511007

Johnston PR, Park D, Ho WW, Alexander BJ (2017) Genetic validation of historical plant pathology records - a case study based on the fungal genus Phoma from the ICMP culture collection. Plant Pathol 66:1424-1431. https://doi.org/10.1111/ppa12728

Marin-Felix Y, Groenewald JZ, Cai L, Chen Q, Marincowitz S, Barnes I, Bensch K, Braun U, Camporesi E, Damm U, de Beer ZW, Dissanayake A, Edwards J, Giraldo A, Hernández-Restrepo M, Hyde KD, Jayawardena RS, Lombard L, McTaggart AR, Rossman AY, Sandoval-Denis M, Shen M, Shivas RG, Tan YP, van der Linde EJ, Wingfield MJ, Wood AR, Zhang Y, Crous PW (2017) Genera of phytopathogenic fungi: GOPHY1. Stud Mycol 86: 99-216. https://doi.org/10.1016/j.simyco.2017.04.002

O'Donnell K, Kistler C, Cigelnik E, Ploetz RC (1998) Multiple evolutionary origins of the fungus causing Panama disease of banana: concordant evidence from nuclear and mitochondrial gene genealogies. PNAS 95(5):2044-2049. https://doi.org/10.1073/pnas.95.5. 2044

Persad C, Fortune M (1989) A new disease of sorrel (Hibiscus sabdariffa var. sabdariffa) caused by Coniella musaiaensis var. hibisci from Trinidad and Tobago. Plant Pathol 38:615-617. https://doi.org/10. 1111/j.1365-3059.1989.tb01460.x

Plotto A (2004) Hibiscus post harvest operations. Food and agriculture organisation of the united nations. http://www.fao.org/fileadmin/ user_upload/inpho/docs/Post_Harvest_Compendium_-_Hibiscus. pdf. Accessed 18 May 2019

Ronquist F, Teslenko M, Van der Mark P, Ayres DL, Darling A, Höhna S, Larget B, Liu L, Suchard MA, Huelsenbeck JP (2012) MrBayes 3.2: efficient bayesian phylogenetic inference and model choice across a large model space. Syst Biol 61:539-542. https://doi.org/10.1093/ sysbio/sys029 